\title{
Imenoslovje in etimologija imen
}

\author{
Dušan Čop (Ljubljana)
}

IZVLEČEK: V prispevku avtor skuša razložiti, na kaj je treba pri etimologiji imen predvsem paziti: treba je do zadnjih podrobnosti poznati narečje in pokrajino, kjer so imena, ki jih raziskujemo, ter zbrati čim več primerov (tudi iz drugih dežel). Prav tako je treba poznati zgodovino kraja, zgodovinske dokumente. Pogosto so lahko odločilne drobne narečne posebnosti. Ob slovanskih imenskih značilnosti pa je pri številnih imenih treba upoštevati tudi križanje z romanskimi in germanskimi.

ABSTRACT: This article seeks to explain what must be taken into account in the etymology of names: one must know the dialect and region of the names studied in great detail, and collect as many examples as possible (including from other countries). In addition, one must know the history of the place and historical documents. Minute special features in a dialect can often be a decisive factor. In addition to Slavic onomastic features, hybrids with Romance and Germanic characteristics must be taken into account for numerous names.

Po letu 1950 se vse bolj razvija veda, ki jo imenujemo imenoslovje (onomasti$\mathrm{ka}$ ). S to vedo se (oziroma naj bi se) ukvarjali predvsem jezikoslovci, kajti po vsem tem, kar smo spoznali doslej, je imenoslovje prav gotovo ena od najtežjih vej jezikoslovne znanosti. Izkušnje, ki nam jih posreduje ukvarjanje s to znanostjo na terenu, nam to v polni meri tudi dokazujejo. Zelo pogosto se namreč zgodi, da naletimo na domačine, to je potomce rodu (rodov), ki v kraju žive že stoletja in ledinska imena poznajo zelo dobro. Ker je njihova narečna izreka neoporečna (čeprav lahko, celo $\mathrm{v}$ isti družini, v določeni meri tudi različna), so mnogi povsem prepričani, da samo oni poznajo pravi izvor imena. Seveda to ni res, kajti da lahko nekdo govori o izvoru tega ali onega imena z vso odgovornostjo, da lahko poda edino veljavno resnico o imenu, da ime pravilno razloži, mora biti jezikovno dovolj izobražen, mora poznati kraj dodobra, in to tudi v smislu zgodovine kraja, o katerem govori (tudi če gre za ledine, vodne tokove, gozdove...), predvsem pa mora biti trezen realist. Imena imajo namreč (že zaradi časovne starosti) dostikrat neprijetne lastnosti, lahko bi v njih našli vrsto izvorov, pravi izvor pa je skoraj vedno samo eden. V takih presoja- 

vrst, pisatelji in celo jezikoslovci), če niso izobraženi v pravi jezikovni smeri in če nimajo pravega vpogleda $\mathrm{v}$ to znanost oziroma intuicije.

V okolici Žalca je ob rečici Pirešici velik travnik, obdan z visokim grmovjem. Imenuje se Loka. Človek, ki je pisal o teh krajih, pravi takole: »Tu so stari Slovani lomili izredno močne veje in iz njih delali loke« (!). Loke, Loka ... so znana in pogosta imena, ki izvirajo iz »lQka«, kar v stcsl. pomeni: »močvirnat travnik ob vodi«. Eden najlepših dokazov za to so veliki in dolgi travniki na desnem bregu Save (od cerkve sv. Klemena proti reki) v južnem, skrajnem koncu vasi Mojstrana v Gornjesavski dolini s skupnim imenom V LONKAH.

Še en tak primer: ob vzhodni obali Bohinjskega jezera je majhen borov gozd, ki mu domačini pravijo mrešše (izgovarjajo tudi mrenše in mrelše) in to izvajajo iz »(žabji) mrest«, ker se prav v tem delu jezera ob obali zbira »mrest«. To seveda ne drži, ker so podobna imena tudi visoko v gorah (npr. Mrešce, kakor se reče gozdu nad planino Lipanca na Pokljuki), tudi blizu Begunj oz. Radovljice je večji mešan gozd z imenom Mrešče. Isto ime najdemo tudi blizu Cerkniškega jezera za večje gozdnato področje. Ime izhaja vsekakor iz »mreža«, vsi kraji s tem imenom vzbujajo vtis, da drevesa stoje v nekakšni pravilni oddaljenosti drugo od drugega, kakor da bi tvorila mreži podobno skupino.

Ime Žirovnica, ki ga mnogi izvajajo iz (bukov) žir, ima čisto drugačen izvor: ime najdemo tudi na Koroškem, v Avstriji, na Češkem, celo v Srbiji (SV od Kragujevca), predvsem pa tudi v prvotni obliki Žrnovnica v Dalmaciji (npr. ob obali blizu Senja in vzhodno od Splita) in to ime lepo kaže pravi izvor iz psl. žъrny, žъrnovъ $=$ mlinski kamen.

Tako ime je tudi Uskovnica (nar. (W)uskounca), planina nad Srednjo vasjo v Bohinju. Domačini trdijo, da je planina razmeroma ozka, da ime izhaja iz »ozek«. Žal je to docela zgrešeno: $v$ radovljiškem urbarju iz leta 1498 je čisto jasno zapisano: LUSKOWINTZA. Prav na tem območju od Bohinja do Jesenic in še naprej proti Kranju najdemo priimek LUSKOVEC; poznamo tudi rastlino, ki se imenuje lusnec - vsa ta imena imajo isti izvor: luska (lusnec je pokrit z luskami).

Omenimo še ime Pišnica (kranjskogorsko »pî̌ñnca《). Mnogi, ki so se ukvarjali s tem imenom, so mnenja, da je ime oblikovano iz »kopišče«, češ da so bila ob reki na več mestih oglarska kopišča (tako trdi tudi J. Voljč v svoji knjigi o Podkorenu iz 1. 1938). Toda kopišča so nastajala $\mathrm{v}$ poznejših stoletjih, ne ob času, ko so se tukaj naseljevali (stari) Slovani. Povejmo kar naravnost: v znamenitem delu »Slovenija na vojaškem zemljevidu $1763-1787$ « je zelo lepo zapisano za vse tri Pišnice (Mala -, Velika -, Suha -): »Peschtschenitza«. To potrjuje tudi dejstvo, da je cesar Franc Jožef dal dvakrat zgraditi jez v zgornjem toku te reke (Velike Pišnice), ker teče po izrazito peščenih tleh. (Tako se tudi še danes dogaja: v hudem deževju konec julija 2000 je reka prenesla svoj tok na peščeni breg ob cesti proti Krnici in odnesla pesek, da je bila cesta na več mestih popolnoma uničena.) Ime ima torej po besedi pesek (stcsl. pěsъkъ), - ̌́- je prešel v domačem govoru v -i-. Mimogrede: Pesnica (potok in kraj severno od Maribora) ima ime po pesku (F. Bezlaj) in ne po povrtnini, ki jo imenujemo pesa.

Pa še Danje naj omenim pri tem osnovnem poglavju mojega prispevka. Vse 
mogoče smo brali o izvoru tega imena: (das ist) meine, (jenes) ist deine (ker so bili prvotni naseljenci iz leta 1283 in pozneje priseljeni iz Južne Tirolske, iz okolice Innichena), drugi menijo, da je ime nastalo iz »dno«, kakor imena več krajev v Sloveniji: Dane ipd., toda kraja Spodnje in Zgornje Danje ne ležita na dnu neke doline ali gorskega kotla, ampak Spodnje Danje na grebenu med dvema dolinama (med Roselpoharsko in Danjarsko grapo), Zgornje Danje pa so vsaj za dobro uro hoda više pod vrhovi Ratitovca! Poleg tega vemo (iz zgodovine tega predela naše Slovenije - prav zato je izredno pomembno, da raziskovalec, imenoslovec zelo dobro pozna tudi zgodovino krajev in naselij, katerih imena raziskuje), da naseljenci teh krajev od 13. do 17. stol. zaradi trdega kmečkega dela na ne preveč rodovitnem območju niso plačevali davka, ki ga pisatelji kot Ivan Tavčar poznajo kot danj. In to je izvor imena Danje (Unter - in Oberhuben). To ime pozna tudi Pleteršnik, vendar besedo zapiše dan.

Kako trezno in realno mora raziskovalec imen presojati vse zgodovinske vire in dostikrat zelo skope podatke, ki so mu dani, da mora biti izredno natančen, da mora biti nadvse razgledan po vsej deželi, zelo dobro, do največjih podrobnosti seznanjen z narečjem in da mora imeti pred seboj čim več primerov, naj pokažejo še imena Farjevec, Zapoden (nar. izg. »za pódnem«), Podvin.

Za Farjevec (pobočje nad Spodnjimi Rutami v Martuljku na karavanški strani) mnogi, tudi sicer resni ljudje, pravijo, da se je tam ubil neki »far«, za Farjevec na desnem bregu Save Bohinjke, nasproti starega zaselka Obrne (pri Bohinjski Beli) sem izvedel pri domačinih, da je bil lepi travnik, ki ga tako imenujejo, v preteklosti kupljen od blejske fare, da pa so tam vedno pasli (mlade) vole; to velja tudi za Farjevec nad Mojstrano oz. pri Vrtaški planini: tudi tam pasejo (mlade) vole - toda voli se pasejo tudi na pobočju Farjevca nad Rutami v Martuljku. Iz stvis. nemščine pa vemo, da so mlademu volu Nemci rekli »Far(r)o«, danes je to nemško »Farre «. Mirno lahko rečemo, da je ime prišlo iz nemščine: Farjevec je torej toliko kot naš »volovljek« ali »volovje«.

Več kakor samo zanimiv pa je primer Za podnem, danes Zapoden. Domačini in obiskovalci Trente (Zapoden je blizu izvira Soče) so prišli do »spoznanja«, da je izvor imena »za poldne(vo)m«. Takole so govorili nekateri: »Z besedo 'poden = dno doline' nima to ime nič opraviti, ker je obrnjena proti jugu, proti poldnevu!« In ravno to je napačno (V knjigi Bovška hiša (M. Kajzelj) je omenjen tudi ta kraj z imenom Zapoudan). Ljudje so se v te kraje naselili (zaradi revščine so morali kopati železno rudo tudi $2000 \mathrm{~m}$ visoko pod Pelci in Mojstrovko) v 16. stol., da so bili bliže »rudnikom«. Ime Za podnem kaže na zelo zanimivo posebnost (zgornjesoškega) narečja - končnica -em (mask.) za šesti sklon, sicer vedno -om. Tudi v češčini in poljščini najdemo isto končnico (npr. za potokem, před Bohem in poljsko: pod kotlem, przed domem). In ta končnica (končni - $m$ se navadno sliši - $n$ !) je v narečju že zelo stara, gotovo pa je iz časov dokončnega izoblikovanja slovenskih narečij: v letu 1409 imamo v historičnih virih tale zapis imena vasi pod Krnom: »Namabisgonden«, 30 let pozneje druga roka zapiše: »Na mali gosden« - vas se v 18. in 19. stol. imenuje oz. zapisuje Mali gozd, zdaj Magozd. K sreči se je oblast odločila za obliko Zapoden - $\mathrm{k}$ temu je treba na kratko še dodati, da poden $\mathrm{v}$ gorskih predelih vedno pomeni »dno doline« do tam, kjer se začnejo gorska pobočja. Zato so tudi v Kara- 

skih govorih poznamo namreč tudi dolge soglasnike oz. podvajanje soglasnikov, npr.: »to je pa Johanna ruta!«, »prane (= perilo) se pa že sší / šší.«. Treba je res zelo dobro prisluhniti, da sogovorca prav slišimo. Geodeti (po domače »žolnirji«), ki so imena popisovali, pa so jih velikokrat zapisali napačno (bili so tujci, med njimi tudi Čehi) prav zato, ker niso poznali narečnih posebnosti. Imamo torej opravka z izredno staro slovansko obliko: sem gotovo spada tudi ime Devin (grad pri Trstu). Blizu Želeč (ime Želeče, del Bleda, je izvedeno iz imena Želimir) je bilo majhno naselje Dindol. Na tej strani hriba Straža je visoka, navpična pečina (taka skala je omenjena tudi pri Podvinu). Ime Dindol je zelo verjetno »devin dol«<»děva«. Ljudje sicer omenjajo vse možnosti (tudi vinograd). Povezovati Podvin z Vintgarjem je huda zmota že zato, ker je bil Vintgar vse do začetka 20. stol. le ime soteske, po zgraditvi poti skozi njo konec 19. stol. (po 1. 1893) je J. Žumer zgradil blizu izhoda zgraditvi poti skozi njo konec 19. stol. (po 1. 1893) je J. Zumer zgradil blizu izhoda
oz. vhoda v sotesko restavracijo Vintgar. Vas v neposredni bližini pa se je vedno, do srede 20. stol., imenovala Leskè, $v$ Leskàh (z naglasom na 2. zlogu - torej ni mogoče, da bi bila soteska dobila ime po vasi, ampak prav obratno). Da je zgodovina oz. da so zgodovinska dejstva res pomemben element pri od-

vankah imena kot Poden, Podnar. - Poldne ni označba za dolino, ampak predvsem za gorske vrhove: blizu tromeje Češka - Avstrija - Nemčija je gorski vrh Polednik (v češčini poledne $=$ poldne, jug), Polinik večkrat v Alpah v Avstriji: gora, ki nad njo sonce stoji točno opoldne $-\mathrm{z}$ mostu med krajema Kötschach (= Hoče, ne Koče, kakor nekateri napačno prevajajo to ime) in Mauthen (= Muta, staro ime) se lepo vidi: točno na jugu je Polinik (= poldnik), malo na levo proti vzhodu Elferkofel in še bolj na levo Zehnerkofel. (Ni pa tega izvora Poludnik v Karnijskih Alpah - ime v Karavankah Trupejevo poldne in Maloško poldne, v Julijcih so Rutarško poldne (zdaj Velika Ponca). Ponce (Mala, Visoka, Srednja, Zadnja) so iz »poldnica«. So pa

Poldnevnice: na meji goriške in tolminske občine, v Beneški Sloveniji.
Na Pokljuki je kraj Meja dolina, ki se v Jožefinskem katastru imenuje Meduedia Dol(l)ina, in to zelo dosledno - v 19. stol. pa je to že Meja dolina. Ni mogoče trditi, da se tu križajo meje posestnikov, izhajamo lahko samo iz Medja dolina (-dje izpadel kakor v ograja < ogradja, zbu(d)jen..). Še po 2. svetovni vojni so se sem zatekali medvedi na svoji poti čez Pokljuko. V bližini je tudi Meji vrh (prav tako iz »medved«). V imenu Medje voše (= medvedje jelše) in imenu sedla Medji dol pa je

Že iz dosedanjih ugotovitev ob imenih, ki sem jih omenil, je razvidno, kako pomembno je, da imenoslovec temeljito pozna zgodovino in posebnosti krajev, s katerih imeni se ukvarja. Tak kraj, ki ima navidezno lahko razložljivo ime, je Podvin, ime starega gradu blizu Radovljice. Omenja se že zelo zgodaj, že leta 1311. Krajev $\mathrm{z}$ istim ali podobnim imenom je veliko: Podvin pri Žalcu, Podvine pri Zagorju ob Savi, Podvinje pri Slavonskem Brodu, Podvin je tudi v Bolgariji in na Slovaškem, .. Nemško ime za kraj je bilo Podwein; zato nekateri mislijo, da je to »v zvezi z vinom«, drugi iščejo zvezo z imenom Vintgar, a to je popolna zmota. Če dobro poslušamo domačine iz kateregakoli kraja na Zgornjem Gorenjskem, kako to ime (1) zgovarjajo, slišimo: »pod dvinam je biu.«, »zei grem pa pod dvin.« ipd. V gorenj(a)

(1)


krivanju pravega izvora nekega imena, kažeta npr. hišno ime Ps(t)nak (v Zg. Radovni pod Triglavom) in krajevno ime Mojstrana.

Ime Pstnak oz. Psnak ne izvira iz pes, ampak je iz posoškega pustina. Na Gorenjskem je to pustota, proti vzhodu pusta, pušča ... torej pomeni pustina pusto zemljišče, kjer ni ne hiše in tudi ne polja, lastnik pa je Pustinak; gorenjsko in koroško je to Pustotnik, Pestotnik, Pistotnik (nar. Pstotnek) - pstuh je človek, ki je pust, živčen. Zapis Pisnak v nekaterih geografskih kartah je torej čisto zgrešen.

Mojstrana pa ni imenovana po mojstrih, ki naj bi bili v tem kraju nekoč nadzirali »bžince« (= fužinice), ki so bile tukaj (kakor tudi v Ratečah in na belopeškem področju...) - vsekakor je do sem in še dlje segal furlanski vpliv. Ime izvira iz *magjustra (F. Bezlaj), kar v st. furl. besedišču pomeni »črnica« oz. borovnica. Da so to besedo tukaj zares poznali že od konca srednjega veka, priča ime travnikov severno od Mojstrane, v smeri proti Savi = »črnîče râvən«, (tudi Črničje ravne): Zgodovina je vsekakor pomemben element pri odkrivanju imen.

Drugo dejstvo, ki je neizogibno povezano z imenoslovjem v Sloveniji (zlasti v zahodnih in severnih predelih), pa je, da so prav geodeti zagrešili hude napake pri zapisovanju imen v nekdanjih avstrijskih katastrih. Potok Plaznica (blizu Krope) je zapisan kot Poznica, potok Hladnik (v Martuljku) pa Hodnik. Če človek ne prisluhne dobro, sliši pač -o- namesto -wa-! Še hujše je, da je ime Žale (na Bledu) zapisano Scherschlach (seveda v gotici) - da omenim le nekaj primerov. A tudi zapis Belo polje (v Bohinju) /namesto Velo -/ je docela zgrešen: v Sloveniji je precej krajev, ki imajo v svojih imenih staro, krajšo obliko za »velik» (Velesovo < Velo selo in ne po imenu nekega božanstva Veles- $a$, u vélmo lêso $=$ v velikem gozdu). - Nekatera imena so zaradi take površnosti in neznanja še danes čisto popačena. Eno od njih je tudi ime potoka Rečica (pod Jelovico), zapisano pa (v že omenjenih katastrskih mapah, a tudi še v novejših, povojnih mapah) Vrčica (F. Bezlaj poskuša to razložiti iz »vrč« ali »vir«, a ne gre!). Primer je res nekaj čisto posebnega: ko so Italijani 1. 1942 objavljali svoje vojaške karte (po napadu na Jugoslavijo in po zasedbi dela Slovenije), so na mejni karti (v škofjeloškem delu Gorenjske) čisto zgoraj, skrajno levo, zapisali ime istega potoka Orciza (= po izgovoru Orčica). Ta imena je težko pravilno razbrati že zato, ker domačini tako rekoč v vsaki vasi drugače izgovarjajo začetni u-, v-, o-, tudi če gre za predlog »v« pred besedo. Tako slišim npr. »u mlîno« (= V mlinu), »u završənc« (=V Završnici), »u rádoun« (=V Radovni), a tudi »o ledinah« (=V Ledinah / Poljče), »O bwâscəx (V blatcih, iz česar je nastalo Obvasca / Doslovče). Obranca je npr. planja na vzhodnem pobočju Mežakle (ime je staro več kot 400 let, ko so se tja ob vpadu Turkov zatekale domače družine in se tu skrivale, branile pred njimi); drugje, npr. na Hrušici, so mi lovci za isto ime govorili V Branci (= u bránc). Ime Vrčica namesto Rečica se pojavlja večkrat, in to ne samo na Gorenjskem. Naj tu samo omenim, da je za »Rečico« v rabi tudi ime Ročica (npr. v Bovcu in na Dolenjskem, a tudi na Gorenjskem) - z »razlago«, da si je tam nekoč neki otrok zlomil ročico ali da je kmet nerodno zavozil z vozom v potok in pri tem zlomil ročico pri vozu.

Da bomo današnje napačne oblike imen prav razumeli, naj tu omenim še dve imeni. Prvo je gorsko ime Vrtača (drugi najvišji vrh v Karavankah, med Stolom in Begunjščico). Ljudje na gorenjski strani (lastniki zemljišč na Zelenici in na po- 
$-\quad$ bočjih teh gora, so bili vedno Slovenci, a tudi na severni strani so vedno živeli le Slovenci. V vaseh na južni strani Karavank ljudje goro imenujejo Nemški vrh (v PV je dolgo vrsto let trajalo razpravljanje o tem imenu - celo pisatelj F. S. Finžgar je v PV trdil, da so njegovi starejši sorodniki goro vedno omenjali le s tem imenom). Na koroški strani goro imenujejo Vrtača, zato so se naši geografi odločili za to ime. Ni pa to pravo ime: Vrtača je kraška dolinica med Stolom in goro s spornim imenom. Temu prastaremu prehodu s Kranjskega na koroško stran, ki pa je v celoti na kranjski strani, vse do mejnega prehoda Belščica, rečejo domačini Čez Vrtačo, kakor je zabeleženo tudi na karti 1:25000 Geodetskega zavoda RS, št. 141 - in očitno so to ime na koroški strani vzeli za gorski vrh. Nihče tega imena ni znal razložiti pravilno. Res je, da je ime Nemški vrh zgrešeno, to pa spet zaradi posebnosti v zgornjesavskem narečju. Prav pri tem imenu se vidi, kako izredno pomembno je, da tisti, ki se ukvarja z imenoslovjem, zares dobro pozna tudi narečje in da je (iz dokumentov) dodobra seznanjen z zgodovino krajev in krajevnih (tudi gorskih) imen. Zelo so v takih primerih uporabni tudi opisi meja starih graščinskih posestev. Prav po imenovanem delu Karavank je tekla meja blejske graščinske posesti. »Stou ... Menischke Werch« (V opisih graščinskih meja so imena zelo dosledno zapisovali v narečnih oblikah!). To ime »Menischke Werch« je zanimiva priča posebnosti v današnjem severozahodnem slovenskem naselitvenem prostoru - metateze so tu kar pogoste. Ime Meniški vrh je prešlo v Nemški vrh (tudi naglas je v tem delu Slovenije dostikrat prešel na prvi zlog), Čomoradnek (rovt pod Stolom) $<$ Močeradnik, ker je tudi močerad > čomorad, Zapret < Zatrep. Gobatec < Bogatec (tolminsko ime za bohinjski Bogatin, Kupljenik (nad Bohinjsko Belo) se 1. 1511 beleži kot Pukl(j)enik, a tudi sicer: gomazin < magazin, potariše < toporišče i. dr. Ime Meniški vrh je v Sloveniji tudi na Štajerskem, SV od Sevnice.

Da brez temeljitega znanja drobnih narečnih posebnosti ni mogoče zanesljivo ugotoviti izvora (ledinskih) imen, dokazuje popačena oblika imena Na Sušeh (= planina nad Srednjo vasjo v Bohinju). Ljudje dosledno govorijo »na sšéx« - nenaglašeni -u- (zlasti v prednaglasnem zlogu) v zgornjegorenjskem narečju dosledno izpada: Suši so v govoru Sši (ali celo Šši) in to ime ni osamljeno (niže na Gorenjskem je to Səší). Tudi hišna imena so »pri sšîunko« (vzporedno pa tudi »pr səšîunko«/ /sušînko«). Na današnjih geografskih in planinskih kartah pa poleg imena Na Sušeh najdemo tudi nesprejemljivo obliko $\mathrm{Na}$ Šehu (kar je brez pravega pomena), Na Sušeh pomeni »kjer so sušili posekana drevesna debla« (ali kaj drugega).

Naj tu ob koncu razprave o posebnostih izvora imen dodam na hitro še nekaj primerov - že zato, ker se tu v Sloveniji križajo tudi vplivi romanskih in nemškega jezika in se prepletajo z zelo starimi slovanskimi imeni. Zato bi morali imenoslovci dobro poznati tudi sosednje romanske jezike, nemščino in njihove narečne posebnosti. Na Koroškem (v vseh narečjih od Vzhodne Tirolske pa do Ruš pri Mariboru) zelo pogosto naletimo na imena Ladine, priimek Ladinek (Ladinig), Wadne... v vseh drugih slovenskih narečjih je to Ledine, Ledinek. Vedeti je treba, da v koroških govorih -e- v ponaglasnem (tudi prednaglasnem) zlogu pogosto preide $\mathrm{v}$-a- (npr. Sadwò = sedlo, jasánovc = jésen; »tam pa drgáče račó«...). To nekateri tuji jezikoslovci popolnoma napačno razlagajo iz »Latinus, Latinicus«. Zato je bil večletni prepir v PV v devetdesetih letih 19. stol.: na Jezerskem danes rečejo: $N a$ 
Vodinah oz. na Vadinah (govor domačinov je koroški - stari zapisi pa dosledno kažejo Ledine, na Ledinah).

Gorskega imena Škrlatica ni mogoče razlagati iz »škrlat(en)《. Nemško ime (die) Scharlachröte in tudi angleško »Scarlet Crag« je zgrešeno! Za pojem »rdeč« domačini nikjer ne uporabljajo »škrlaten«, imamo pa za »rdeč« vrsto izrazov, ki so ostali v imenih do danes! Blizu meje Zgornje Avstrije in nemško govoreče Štajerske je kraj z imenom Rottenmann, ki se v 13. stol. imenuje še Zirminach, na pobočju pod gorskimi vrhovi Dovški križ, Škrnatarica v Škrlatičini skupini sta jarka dveh hudournikov: Mali in Veliki Čr(v)lovec. Če si ogledamo pesek okrog »izvirov« teh hudournikov, ki ima izredno nežno svetlo rdečo barvo, nam je takoj jasno, odkod njuno ime: Že Megiser pozna zherlen = rdeč, Ramovš opozarja na čъrvlenъ in *čъrmъnъ. - Tudi imena Krvavec, Krvavka (vzhodni vrh Golice v Karavankah), Krvava peč idr., ne samo Rdeča skala, nam povedo, da je tu mišljena rdeča barva.

Dr. H. Tuma je v Imenoslovju Julijskih Alp in v drugih spisih večkrat zagrešil hude napake: Tako je $\mathrm{v}$ Karavankah oz. na njihovih pobočjih našel tudi taka imena kot Male deva; to je zanj napaka - pisati je treba, pravi, Mala deva. Prav to dokazuje, da Tuma narečja sploh ni poznal: Male déwa v zgornjegorenjskem narečju pomeni »Mali deli« oz. male parcele (gozdne - , poljske - ). Značilnost zgornjegorenjskega narečja (tako je tudi drugje, vendar v manjši meri) je, da moški in ženski spol samostalnika preideta v množini v srednji spol (zato v govoru: Spodnje Gorjuša, Zgornje ..., Zdénšca = Studenčice; »tam so pa tri xîša za trî držina«). Če stoji spredaj pridevnik, je ta navidezno $\mathrm{v}$ ženski obliki. Male deva torej tudi ne pomeni »mala dela«, kakor nekateri mislijo, ampak na Spodnjem Gorenjskem (npr. v okolici Kranja) beremo v geodetskih kartah: Mali deli, Veliki deli, tako tudi za Šmarno goro, čeprav so vmes tudi tukaj napake; da gre res za del = parcelo, nam lepo pove beseda »part« (gozdna parcela, romansko), v okolici Bleda, ta(j)1 v Bohinju (germansko / nemško) in tudi v Gornjesavski dolini.

Ime slapa Boka pri Bovcu ne izvira iz dejstva, da je slap na pobočju kaninskih gora, ampak iz ital. la bocca (usta, ustja), zaliv pred mestom Cannes v Južni Franciji se imenuje La Bocca in tudi prvi del imena Boke Kotorske je tega izvora. (V Hercegovini je večkrat »vrelo Boka«.)

Ime kraja Srpenica (ob Soči) ne izvira iz »srp«, ampak iz »stirpe« (to v ladinskem jeziku pomeni »jalovo govedo«; 1.1496 se v odločbi Goriškega mejnega grofa ta kraj imenuje Sterpeniza (istega izvora je ime kraja Stirpnik - v hribih nad Škofjo Loko; malo znano je, da se vršnji deli nekaterih srednjevisokih hribov imenujejo Frtica (npr. Višelnica nad Gorjami pri Bledu; pri Drenovem Griču, pri Litiji, hrib nad Grosupljim!) < fortitia.

Priimek Kverh (v vaseh med Bovcem in Trento) ne izvira iz »Gewerk« (ker so v Trenti od 16. stol. do 18. stol. imeli železarske fužine zaradi rudnikov pod Pelci in Mojstrovko), ampak iz Quarg, kar je slovensko Žmitek (prav ta priimek, lepo slovenski, ni < Schmid, kakor nekateri zmotno mislijo, je najti na kamnogoriškem področju, a tudi v Bohinju). Končni -g v nemških besedah je -x- $\mathrm{v}$ izreki, kratkonaglašeni -a- pa je v zgornjesoškem narečju -è- (npr. brèt, brátra).

Ker se ne spoštuje narečja in njegovih zakonov, se pri nas mnogo imen piše napačno. Tudi ni res, da bi tisti, ki so veliko pisali o naših krajih in gorah (npr. dr. 
$4 \quad$ H. Tuma) pisali vselej pravilno. Po mojem mnenju bi morali napake popraviti in tako ohraniti prvotno, staro, resnično pravo obliko imen. Zlasti še zato, ker domačini dosledno uporabljajo svoja, stoletja stara imena, zaradi česar pride do nerodnih primerov, da turisti zaradi napak v zemljevidih krenejo po napačni poti. Naša imena je treba pisati v knjižnem jeziku in njihovem pravem pomenu - to nam lepo prikazuje duha in mišljenje naših davnih prednikov in njihov odmev - njihove usode vse do današnjih dni. To je eden najdragocenejših dokazov o slovenski prisotnosti v Vzhodnih Alpah. Da ne bomo nekega dne prisiljeni reči tako, kakor pravijo keltski Valižani v svojem pregovoru: Cenedl heb iaith cenedl heb galon ${ }^{1}$.

\title{
Viri in literatura
}

Badjura, Rudolf, Ljudska geografija (Terensko izrazoslovje) I, II, Ljubljana 1953, 1957.

Bezlaj, France, Etimološki slovar slovenskega jezika I, II, III, IV, Ljubljana 1976, 1982, 1995, 2005.

Bezlaj, France, Slovenska vodna imena I, II, Ljubljana 1956, 1961.

Čop, Dušan, 1983, Imenoslovje zgornjesavskih dolin, Disertacija, Ljubljana, Tipkopis.

Čop, Dušan, 1995, Jezikovne in imenske značilnosti okrog Krope in v dolini Lipnice, Kroparski zbornik, Ob 100-letnici Plamena, Kropa, Radovljica, Muzeji radovljiške občine, 190-197.

Čop, Dušan, 2002, Gorska, terenska (ledinska) in vodna imena v Sloveniji, Jezikoslovni zapiski 8/2, Ljubljana, ZRC SAZU, 93-108.

Klemše, Vlado, Krajevna, ledinska in vodna imena v Števerjanu, Gorica 1993.

Mrdavšič, Janez, Krajevna in domača imena v Mežiški dolini, Ravne na Koroškem 2001.

Tuma, Henrik, Imenoslovje Julijskih Alp, Ljubljana 1929.

\section{Onomastics and the Etymology of Names}

\author{
Summary
}

Onomastics is one of the most demanding linguistic disciplines. In their assessment of the origin of names, both locals, who think they know the names, and highly educated people are almost always mistaken. The author seeks to explain where attention must especially be directed in the etymology of names. First, one must know the dialect and region of the names studied in great detail, and collect as many examples as possible (including from other countries). In addition, one must know the history of the place and historical documents. In this regard, one 
must bear in mind that surveyors (from abroad) often made gross errors in past centuries because they did not know the local language and its dialects. Minute special features of a dialect often played a decisive role (especially in the cases of Vrčica, Vrtača, and Vintgar). In Slovenia and ethnically Slovenian areas, Slavic onomastic features formed hybrids with many Romance and Germanic features. The consequences of all these issues are numerous mistakes, as demonstrated by the examples presented. 